\title{
Estimation of Vmax in Auxotonic Systoles from the Rate of Relative Increase of Isovolumic Pressure: $(\mathrm{dP} / \mathrm{dt}) \mathrm{kP}$
}

\author{
Michaei J. Wolk, John F. Keefe, Oscar H. L. Bing, Lawrence J. Finkelstein, and \\ Herbert J. LeVINE \\ From the New England Medical Center Hospitals and the Department of \\ Medicine, Tufts University School of Medicine, Boston, Mass. 02111
}

\begin{abstract}
A B S T R A C T High speed oscilloscopic recordings $(4000 \mathrm{~mm} / \mathrm{sec}$ ) of left ventricular pressure (micromanometer) and its first derivative were used to calculate contractile element velocity (Vce) during the isovolumic period of auxotonic beats in anesthetized dogs. At $0.5-2.0 \mathrm{msec}$ intervals of isovolumic systole, Vce was derived as $(\mathrm{dP} / \mathrm{dt}) / \mathrm{kP}$, where $\mathrm{k}=24 \mathrm{~cm}^{-1}$. Plots of Vce and $\mathrm{P}$ yielded inverse curves from peak Vce to aortic valve opening pressure which averaged $27 \mathrm{msec}$ in controls, and $11 \mathrm{msec}$ during norepinephrine administration. Extrapolated Vmax, in muscle lengths/second, averaged 3.6 (controls), 3.6 (volume load), and 6.6 (norepinephrine). In each experimental state, Vmax was also determined from force-velocity relations of isovolumic beats (abrupt aortic occlusion) analyzed at 10 msec intervals from conventional pressure recordings. Vmax by both methods correlated well $(r=0.88)$. While good correlations were also noted between $V \max$ and maximum $\mathrm{dP} / \mathrm{dt},(\max \mathrm{dP} / \mathrm{dt}) /$ integrated isovolumic pressure, $(\max \mathrm{dP} / \mathrm{dt}) /$ peak isovolumic pressure, and $(\max \mathrm{dP} / \mathrm{dt}) / \mathrm{kP}$, only the last two of these successfully distinguished changes between volume load and inotropic stimulation. Thus, assuming an unchanged series elasticity, the contractile state of the auxotonic ventricle may be determined utilizing a single high-fidelity catheter system and high speed recordings of isovolumic pressure.
\end{abstract}

\section{INTRODUCTION}

The contractile state of the myocardium can be characterized by the instantaneous relationship between developed force and contractile element velocity, provided that information regarding muscle length and time are

This work was presented in part at the Annual Meeting of the American Society for Clinical Investigation, Atlantic City, N. J., 4 May 1969.

The authors, except Dr. Levine are trainees, Graduate Training Program 4T1 5391 of the National Heart Institute.

Received for publication 3 March 1970 and in revised form 1 February 1971. known. Although this concept was developed from studies of isolated skeletal muscle (1), its application to papillary muscle $(2,3)$ and subsequent extension to the intact heart (4-6) has reoriented the physicians' search for a sensitive and easily measurable index of the contractile state of the myocardium.

Podolsky (7) has suggested that the rate at which energy is released at the force-generating sites within the sarcomere of heart muscle determines the contractile state, and that the mechanical equivalent of this rate constant is the velocity of the unloaded contractile element (Vmax). In studies of papillary muscle, changes in the inotropic state have been identified with changes in $\operatorname{Vmax}(2,3,8)$ and the ability to examine high velocities at small loads in these experiments has permitted Vmax to be determined with considerable accuracy. In the intact heart, Vmax has been derived from instantaneous force-velocity relations of both auxotonic and isovolumic beats $(5,6,9)$. In the case of auxotonic systoles, however, these analyses require elaborate methods for measuring instantaneous dimensions of the heart and necessitate calculations of wall stress. Analysis of isovolumic beats, while simpler and less subject to error, is not applicable to human study.

Recently, Mason (10) obtained Vmax from auxotonic systoles by extrapolation of a plot of contractile element velocity $(\mathrm{Vce})^{1}$ and pressure during the isovolumic period. The advantages of this technic are that only a single high fidelity catheter system is required, and measurements of ventricular dimensions and wall thicknesses are not necessary. The major disadvantage of this method lies in the fact that the segment of the isovolu-

${ }^{1}$ Abbreviations used in this paper: AOP, aortic pressure; AVO, aortic valve opening; IIP, integrated isometric pressure; LV, left ventricle; LVP, left ventricular pressure; $(\max \mathrm{dP} / \mathrm{dt})$, maximum rate of pressure change; $P$, pressure; PIP, peak isovolumic pressure; Vce, contractile element velocity. 
mic period used to extrapolate Vmax is generally only $20-35 \mathrm{msec}$ in duration and frequently is shorter. Thus, accurate measurements from conventional pressure recordings are difficult to obtain and too few in number to provide satisfactory determinations of Vmax.

In the present study, high speed oscilloscopic recordings $(2000-4000 \mathrm{~mm} / \mathrm{sec})$ of isovolumic pressure and its time derivative have been utilized to construct curves of contractile element velocity and pressure. While the duration of the inverse segment of these curves was extremely short, the clearer definition of the time course of pressure and its first derivative permitted calculation of Vce at intervals as short as $0.5 \mathrm{msec}$ of isovolumic systole. Although the accuracy of pressure measurements is not increased by these high speed recordings, the ability to identify instantaneous values of pressure and its first derivative is greatly enhanced. In addition to Vmax, other indices of contractility, derived from an analysis of preejection time-intervals and single derivatives of isovolumic pressure, were examined.

\section{METHODS}

12 adult mongrel dogs weighing $15-25 \mathrm{~kg}$ were anesthetized with intravenous sodium pentobarbital $(25 \mathrm{mg} / \mathrm{kg})$. Respirations were driven by a Harvard pump (Harvard Apparatus Co., Inc., Millis, Mass.) attached to a cuffed endotracheal tube. Polyethylene catheters were placed in the inferior vena cava and ascending aorta. A sternal split toracotomy was performed and a square wave electromagnetic flowmeter (model 300, Carolina Medical Electronics, King, N. C.) positioned snugly on the aortic root as close to the aortic valve as possible. Aortic valve opening pressure was determined as central aortic end-diastolic pressure or from the timing of the onset of the aortic root flow curve. All left ventricular pressures were recorded using an SF-1 micromanometer which was passed retrograde through the aortic valve. The frequency response of this manometer is flat to $90 \mathrm{cps}$ and there is a zero phase lag over this range. The SF-1 transducer was calibrated in situ by attaching its fluid-filled lumen to a Statham P23Db (Stratham Instruments, Inc., Los Angeles, Calif.) pressure transducer and adjusting the amplitude of a micromanometer signal to match that of the $\mathrm{P} 23 \mathrm{Db}$. The first derivative of pressure was determined using an analogue differentiating circuit. ${ }^{2}$ The response characteristics of this differentiator exhibited a phase shift of $90 \pm 1^{\circ}$ to a sine wave input from $0-160$ cps and amplitude was a linear function of frequency (9). Utilizing a sine wave generator (Hewlett-Packard $3300 \mathrm{~A}$ Function Generator, Hewlett-Packard Co., Berkeley, N. J.) and filtering the differentiated cosine signal at frequencies greater than $200 \mathrm{cps}$, a maximum phase lag of $1 \mathrm{msec}$ was observed for input signals up to $100 \mathrm{cps}$. Left ventricular pressure and its first derivative were recorded simultaneously on an Electronics for Medicine DR8 (Electronics for Medicine, White Plains, N. Y.) at paper speeds of 200 $\mathrm{mm} / \mathrm{sec}$, and via output cables on a Tektronix 502A (Textronix, Inc., Beaverton, Ore.) dual beam oscilloscope at sweep speeds of $2000-4000 \mathrm{~mm} / \mathrm{sec}$. Using the electrocardiogram to trigger, the events of the isovolumic con-

${ }^{2}$ Universal Differentiator, Model UD-20, Crane Bio-Medical Instruments, Inc., Elmont, N. Y. traction period were photographed on the oscilloscope with a Hewlett-Packard 196A camera. The pressure derivative ( $\mathrm{dP} / \mathrm{dt}$ ) was calibrated on both the DR8 tracings and the oscilloscopic photographs by equating the graphic maximum rate of pressure change $(\max \mathrm{dP} / \mathrm{dt})$ to the peak height of the derivative curve.

Isovolumic contractions of the ventricle were produced by abrupt occlusion of the aorta during diastole (11). These were analyzed only when zero flow was recorded by the aortic root flowmeter and when peak isovolumic $\mathrm{dP} / \mathrm{dt}$ was the same as the previous auxotonic beats. In 12 experiments in which volume loading was achieved using $300 \mathrm{ml}$ portions of high molecular weight dextran, heart rate was maintained constant by atrial pacing slightly in excess of the dog's sinus rate. Inotropic stimulation of the heart was accomplished in two stages by a constant infusion of norepinephrine $(1-6 \mu \mathrm{g} / \mathrm{min}$ and $4-12 \mu \mathrm{g} / \mathrm{min})$. Left ventricular enddiastolic volume was measured by the thermal dilution technic. The standard error and reproducibility of the volume method has been presented elsewhere (5).

\section{Calculations}

Assuming that isovolumic systole approximates an isometric contraction, isovolumic contractile element velocity (Vce) may be equated to the lengthening velocity of the series elastic component. Thus, Vce, in muscle lengths/second equals $(\mathrm{dP} / \mathrm{dt}) / \mathrm{kP}$, where $\mathrm{k}$ is the normalized modulus of series elasticity of the intact dog left ventricle and has been found experimentally to average $24 \mathrm{~cm}^{-1}$ per cm muscle length (12).

Using oscilloscopic photographs of simultaneous $\mathrm{P}$ and $\mathrm{dP} / \mathrm{dt}$, Vce was calculated at $0.5-2.0 \mathrm{msec}$ intervals throughout isovolumic systole of auxotonic beats (Fig. 1). Plots of Vce and $P$ yielded inverse curves from peak Vce to aortic valve opening which generally permitted a clear extrapolation to Vmax (Vce at zero load). Since normalized Vmax is independent of load, calculation of wall stress or force is not required. Indeed, it is not even necessary to calculate absolute values for $\mathrm{P}$ or $\mathrm{dP} / \mathrm{dt}$ as long as the derivative is calibrated with reference to the pressure.

In isovolumic beats, plots of Vce and pressure were constructed at $10 \mathrm{msec}$ intervals from the onset of left ventricular pressure rise to maximum isovolumic pressure, using photographic recordings (Electronics for Medicine) at paper speeds of $200 \mathrm{~mm} / \mathrm{sec}$. The shape of the inverse curve constructed from both auxotonic and isovolumic beats was concave upwards and varied from almost linear inverse relationships to shallow concave curves. For this reason, extrapolation of the curve to the velocity axis was accomplished by hand and consisted of a smooth extension of the best line drawn through the coordinates of the inverse relationship of Vce and pressure.

In an effort to test the validity of manual extrapolation in the present study, all curves were reexamined and the measured pressure-velocity coordinates subjected to least squares analysis. In this manner, each Vmax extrapolated manually was compared to that calculated mathematically from curve analysis using a linear equation and a polynomial equation of the second degree. The average value for $V \max$ derived by manual extrapolation was slightly higher than that calculated mathematically from a linear equation $(4.4 \pm 0.23$ SEM and $3.9 \pm 0.29$ lengths/sec respectively). However, a very high correlation was observed between these two methods of extrapolation $(\mathrm{r}=0.95, P<0.001)$. When Vmax was calculated using the polynomial analysis of the measured coordinants of pressure and velocity $(y=a+b x+$ 

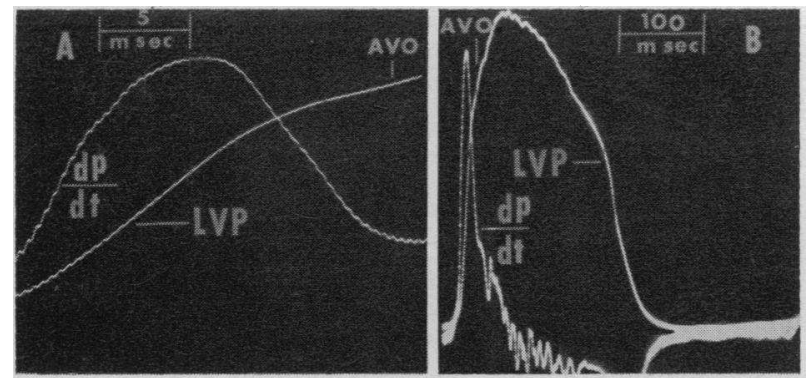

Figure 1 A. High speed $(4000 \mathrm{~mm} / \mathrm{sec})$ oscilloscopic recording of isovolumic left ventricular pressure and $\mathrm{dP} / \mathrm{dt}$. B. Same parameters recorded at conventional sweep speeds $(200 \mathrm{cc} / \mathrm{sec})$. Vertical lines indicate moment of aortic valve opening (AVO). Peak ventricular pressure $=90 \mathrm{~mm}$ $\mathrm{Hg}$ and maximum $\mathrm{dP} / \mathrm{dt}=3380 \mathrm{~mm} \mathrm{Hg} / \mathrm{sec}$.

$c x^{2}$ ), a less favorable correlation with manual extrapolation was obtained $(r=0.61, P<0.001)$, although the mean values were very close $(4.4 \pm 0.23 \mathrm{SEM}$ and $4.0 \pm 0.20$ lengths/ $\mathrm{sec})$. It would seem, that manual extrapolation of Vmax provides values of this intercept which agree closely and consistently with those obtained from computer analysis of isovolumic pressure-velocity measurements.

Other calculations. Time intervals were measured from the beginning of the deflections in electrocardiographic tracing (QRS) of the electrocardiogram to the onset of left ventricular pressure rise (electromechanical delay), to peak $\mathrm{Vce}$, to $\max \mathrm{dP} / \mathrm{dt}$, and to aortic valve opening. The interval from onset of ventricular pressure rise to $\max \mathrm{dP} / \mathrm{dt}$ (time to $\max \mathrm{dP} / \mathrm{dt}$ ) was also measured. (Max $\mathrm{dP} / \mathrm{dt}) / 24 \mathrm{P}$ was calculated by dividing the maximal rate of pressure rise by the ventricular pressure which existed at that instant. (Max $\mathrm{dP} / \mathrm{dt}$ )/peak isovolumic pressure (PIP) was derived by di- viding the numerator by the aortic end-diastolic pressure in millimeters of mercury. The integrated isometric pressure (IIP) was calculated as one-half the product of the isovolumic period, in seconds, and the aortic end-diastolic pressure, in millimeters of mercury. Since this expression assumes a constant isovolumic $\mathrm{dP} / \mathrm{dt}$, IIP is only approximated by this method of calculation. The second derivative of left ventricular pressure was determined arithmetically to identify the time at which max. $\mathrm{d}^{2} \mathrm{P} / \mathrm{dt}^{2}$ was achieved. All data are presented as mean \pm standard error of the mean and the Student's $t$ test was used in the analysis of paired and unpaired data.

\section{RESULTS}

Determination of Vmax. A high speed oscilloscopic recording of isovolumic left ventricular pressure and its time derivative is shown in Fig. $1 \mathrm{~A}$. For comparison, the same events recorded at conventional speeds (200 $\mathrm{mm} \mathrm{sec)}$ are shown in Fig. $1 \mathrm{~B}$. Using the high speed recordings, plots of Vce vs. $P$ were constructed at $0.5-2.0$ msec intervals of isovolumic systole as illustrated in Fig. $2 \mathrm{~A}$. Vmax was then determined by extrapolation to zero P. Additionally, in each state, isovolumic beats were produced by abrupt aortic occlusion and Vce vs. $\mathrm{P}$ plots constructed at $10 \mathrm{msec}$ intervals from conventional slow recordings (Fig. $2 \mathrm{~B}$ ).

In 35 experimental states (nine animals), Vmax from auxotonic systoles correlated well with Vmax derived from isovolumic beats $(r=0.88)$, and the mean of the former was only $4.5 \%$ higher than that of the latter (Fig. 3). This difference was nonsignificant. In the control state, the average $V \max$ (auxotonic beats)

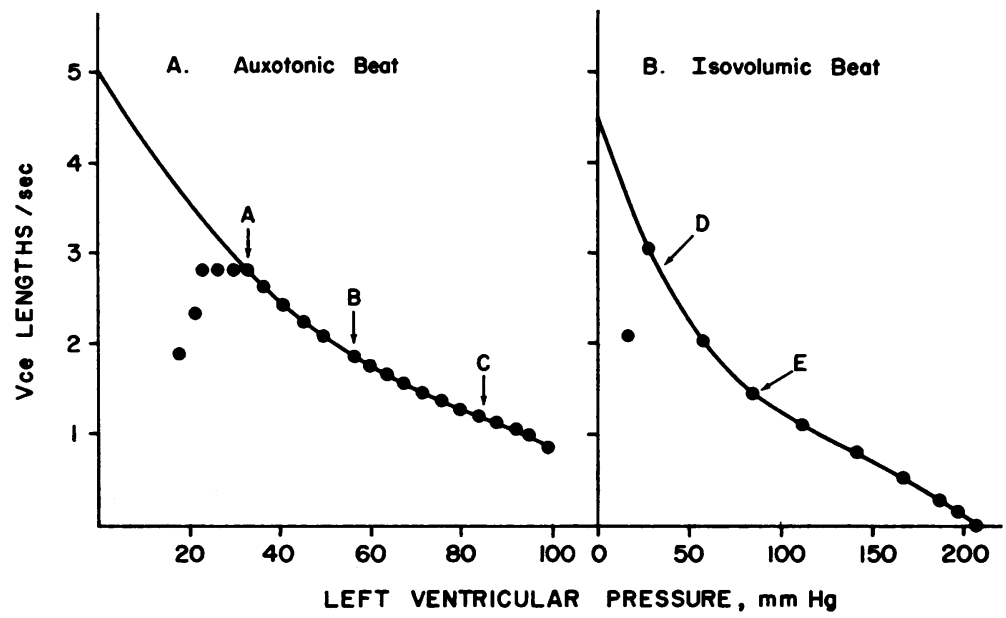

FIGURE 2 A. Vce-pressure plot of an auxotonic beat constructed at 1.5 msec intervals of isovolumic systole. Point $A$ represents peak Vce, point $B$ the time of maximum $\mathrm{dP} / \mathrm{dt}$, and point $C$ the moment of aortic valve opening. The inverse curve described from $A$ to $C$ is extrapolated to zero pressure to determine $V \max$. B. Vce-pressure plot of an isovolumic beat (same experimental state as 2A). Measurements were made at $10 \mathrm{msec}$ intervals to peak left ventricular pressure from conventional recordings $(200 \mathrm{~mm} / \mathrm{sec})$. The segment $\mathrm{D}-\mathrm{E}$ corresponds to the same isovolumic interval $A-C$ in Fig. $2 \mathrm{~A}$. 


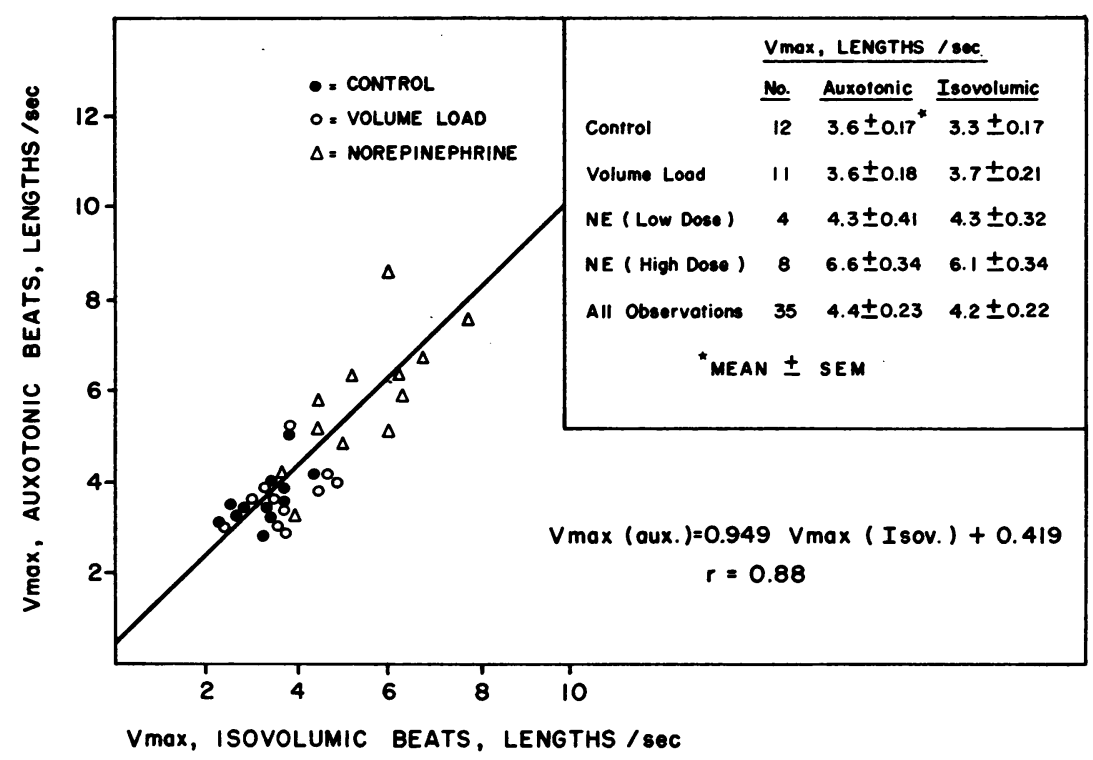

Figure 3 Correlation of Vmax determined from the isovolumic segment of autotonic systoles with that derived from isovolumic contractions of the left ventricle.

of these open-chested dogs, with a mean heart rate of $140 \pm 8$ beats $/ \mathrm{min}$, was $3.6 \pm 0.2$ muscle lengths $/ \mathrm{sec}$. In 10 of 12 observations, Vmax was between 3 and 4 muscle lengths/sec. Volume loading produced no significant change in $V \max$, while intense inotropic stimulation with norepinephrine resulted in values as high as 8 muscle lenghts/sec. In all states, left ventricular systolic pressure in auxotonic beats ranged from 78 to 226 $\mathrm{mm} \mathrm{Hg}$ and end-diastolic pressure varied between 1 and $6 \mathrm{~mm} \mathrm{Hg}$. Peak isovolumic pressure averaged $103 \mathrm{~mm}$ $\mathrm{Hg}$ and varied between 55 and $175 \mathrm{~mm} \mathrm{Hg}$.

Preejection time intervals. A schematic representation of the preejection time intervals is shown in Fig. 4. The electro-mechanical delay, timed from the beginning of the QRS to the onset of left ventricle (LV) pressure rise, was $26.1 \pm 4.1 \mathrm{msec}$ and was not altered by norepinephrine. The isovolumic period averaged $61.1 \pm 2.3$ msec and was reduced to almost half this value by norepinephrine administration. Peak Vce always occurred before maximum $\mathrm{dp} / \mathrm{dt}$, preceding the latter by an average of $13.9 \pm 2.5 \mathrm{msec}$ in control studies. Maximum $\mathrm{dp} / \mathrm{dt}$ was observed $70.5 \pm 5.3 \mathrm{msec}$ after inscription of the $\mathrm{QRS}$, and this was shortened to $52.9 \pm 1.9 \mathrm{msec}$ by norepinephrine. In every instance maximum $\mathrm{dp} / \mathrm{dt}$ was noted before aortic valve opening, preceding it by an average of $12.1 \pm 1.9 \mathrm{msec}$ in the control state. The duration of the inverse plot of Vce and $P$ (from peak Vce to aortic valve opening) averaged $26.8 \pm 2.7 \mathrm{msec}$ in control studies and was sharply reduced by norepinephrine administration to $11.1 \pm 3.3 \mathrm{msec}$. Shortening of the isovolumic period by norepinephrine was more pronounced in the interval after peak Vce $(-59 \%)$ than in the interval preceding peak Vce $(-39 \%)$.

In 10 experimental states, the second derivative of left ventricular pressure was plotted against time. In each instance, peak Vce was clearly defined and fell on the inverse Vce-pressure curve. The peak calculated $\mathrm{d}^{2} \mathrm{p} / \mathrm{dt}^{2}$ occurred $2.4 \pm .9 \mathrm{msec}$ before the time of peak Vce.

Indices of contractility. Correlations between Vmax, determined from auxotonic systoles and eight other indices of contractility were examined. Equally good correlations were observed between $V \max$ and peak Vce $(\max \mathrm{dP} / \mathrm{dt}) / 24 \mathrm{P},(\max \mathrm{dP} / \mathrm{dt}) / \mathrm{PIP},(\max \mathrm{dP} / \mathrm{dt}) /$ IIP, and $\max \mathrm{dP} / \mathrm{dt}(\mathrm{r}=0.84-0.87)$. Less good correlations were found between $V \max$ and the preejection time intervals : time to $\max \mathrm{dP} / \mathrm{dt}$, the isovolumic contraction period, and the duration of the inverse Vce-pressure curve ( $r=0.70,0.77$, and 0.63 respectively).

The failure of this statistical analysis to discriminate between the above indices of contractility is best demonstrated by examining the effect of changes in ventricular preload and inotropic state separately. In these studies, heart rate was maintained constant by atrial pacing. As shown in Fig. 5, volume loading produced no significant change in $V \max ,(\max \mathrm{dP} / \mathrm{dt}) / 24 \mathrm{P}$, and $(\max$ $\mathrm{dP} / \mathrm{dt}) / \mathrm{PIP}$. On the other hand, significant increases in $\max \mathrm{dP} / \mathrm{dt}(+61 \%)$ and $(\max \mathrm{dP} / \mathrm{dt}) / \mathrm{IIP}(+38 \%)$ were observed without change in the contractile state ( $P<0.001$ and $\mathrm{P}<0.05$ respectively). Control left ventricular volume averaged $41 \mathrm{cc}$ (range $27-54 \mathrm{cc}$ ). The volume increase produced in these studies averaged 
$+41 \%$ above control and ranged from 12 to $107 \%$. During norepinephrine administration $\mathrm{V} \max$ increased $62 \%$ and an almost identical increase in $(\max \mathrm{dP} / \mathrm{dt}) /$ $24 \mathrm{P}$ was observed.

\section{DISCUSSION}

Recent efforts to assess the contractile state of the left ventricle in intact animals or humans have involved, for the most part, measurements of single, instantaneous force-velocity relations during the isovolumic period or during the period of ejection. By means of cinefluoroscopy of metal clips sewn to the ventricle at the time of cardiac surgery, Glick, Sonnenblick, and Braunwald (13) measured fiber shortening rate at an instant when series elastic velocity was felt to be insignificant and analyzed pressure-velocity relations at a constant fiber length in a given subject. This technic has been found useful in demonstrating the inotropic effect of digitalis in the nonfailing human heart (14). While these methods are useful in examining changes in the contractile state of a given heart, if one is to compare one heart to another, it is necessary to normalize the myocardial force which exists at the moment that Vce is measured. This requires an accurate technique for measuring left ventricular volume and mean wall thickness, as well as an assumption regarding the geometry of the ventricle. Using catheter-tip micromanometers and cineangiographic technics for measuring ventricular volume and wall thickness, Gault, Ross, and Braunwald (15) derived myocardial wall stress (force/unit cross-sectional area of muscle) and Vce in patients with and without myocardial disease. Although normalized values for force and velocity are obtained by these methods, single values in a given patient cannot characterize reliably the contractile state of the heart. Since any given relationship between Vce and stress provides a single point on the force-velocity curve of that systole, it it not possible to determine Vmax without knowing more about the shape of the force-velocity curve.

Although Vmax cannot be measured directly, determination of this intercept of the force-velocity curve is particularly desirable not only because it provides an accurate means of characterizing the contractile state of myocardium, but because it is in itself independent of ventricular dimensions, wall thickness, and load. This view, however, has recently been challenged by Noble, Bowen, and Hefner (16). Studying cat papillary muscle by quick release force-velocity relations, these workers found that Vmax was indeed length dependent. Because of this observation an effort was made in the present study to examine the effect of abrupt changes in fiber

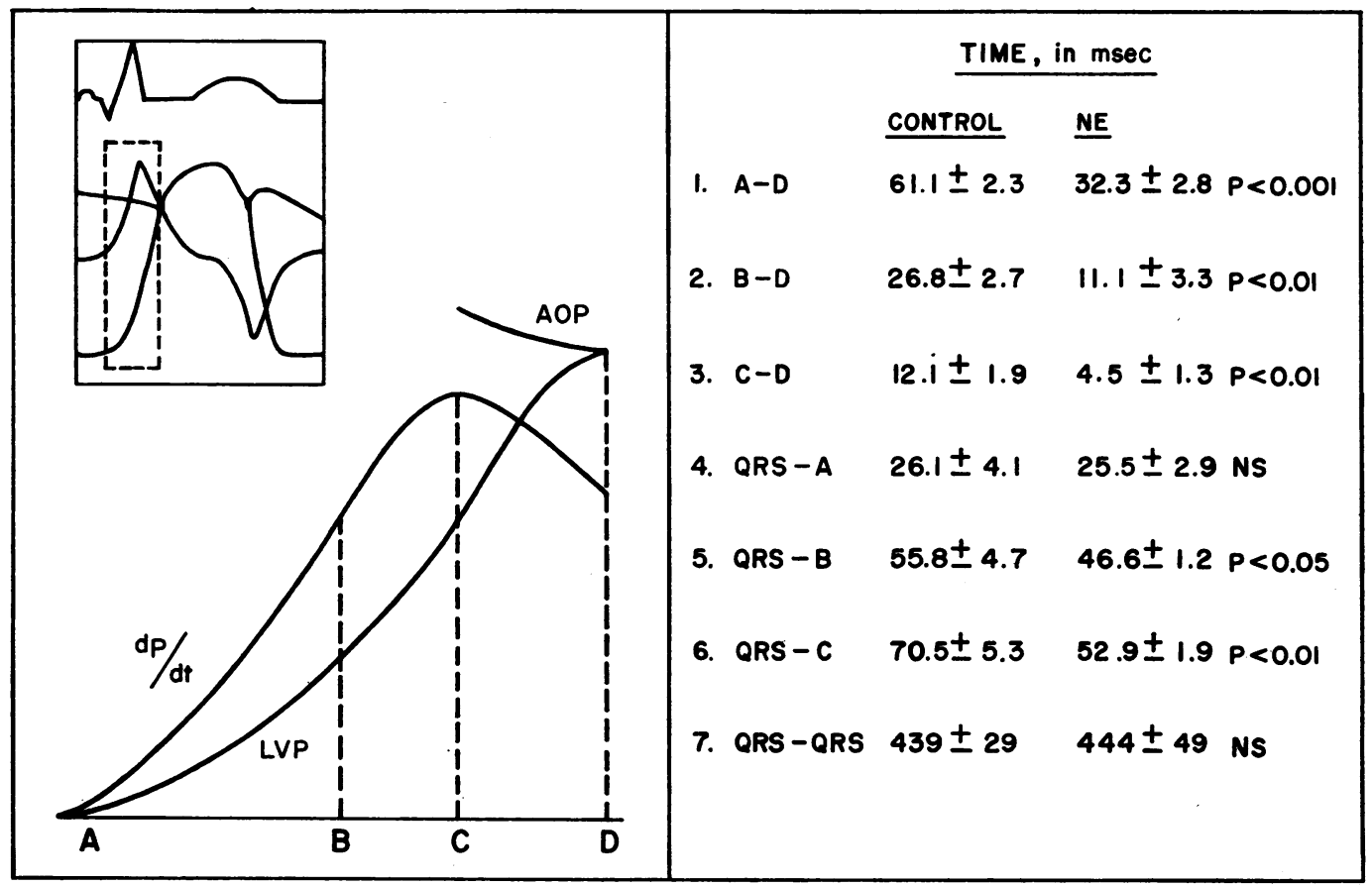

FIGURE 4 Schematic representation of the preejection time intervals. LVP, left ventricular pressure; AOP, aortic pressure. Point $A$ indicates the onset of LVP rise, point $B$ the moment of peak Vce, point $C$ the time of $\max \mathrm{dP} / \mathrm{dt}$, and point $D$ the end of the isovolumic contraction period. QRS indicates the time of the initial positive or negative deflection of ventricular depolarization. 


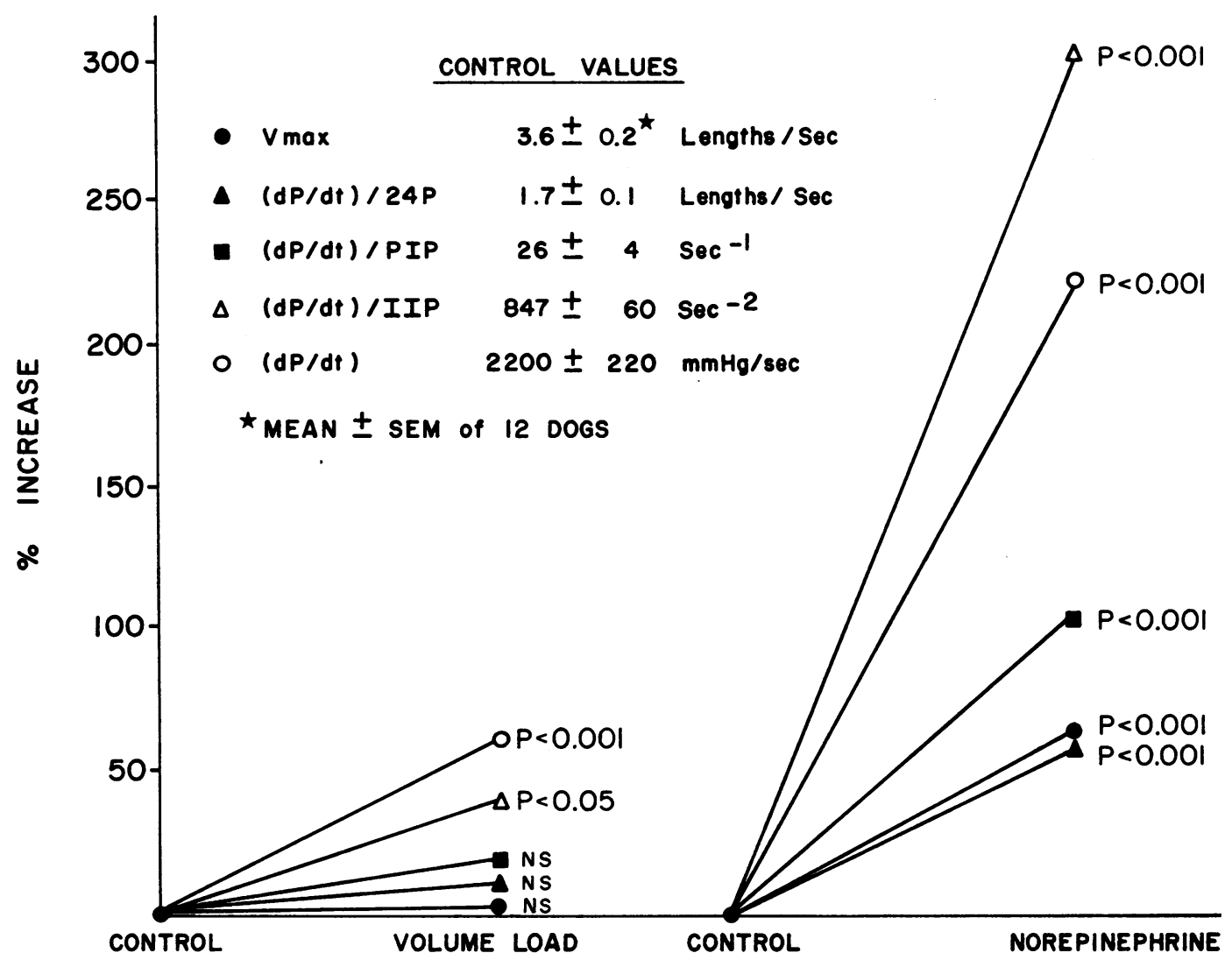

Figure 5 The effect of volume loading and of norepinephrine administration upon changes

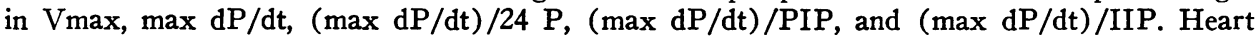
rate maintained constant by atrial pacing. (See text.)

length upon extrapolated Vmax. Abrupt diastolic evacuation of the left ventricle was accomplished through a large bore cannula placed in the apex. When the extrapolated Vmax of the systole just preceding diastolic evacuation was compared to that of the first systole after the diastolic withdrawal of blood, no significant difference was observed. In seven experiments where abrupt evacuation of 10-15 cc of blood was accomplished, extrapolated Vmax of the control beat and the reduced preload beat was 3.8 and 3.9 lengths/sec respectively $(P=\mathrm{NS})$. These reductions in preload were associated with a fall in $\max \mathrm{dP} / \mathrm{dt}$ of $15-30 \%$. Thus, using the methods described, changes in Vmax could not be detected when diastolic volume was abruptly lowered.

It should be noted that Vce in all these experiments has been calculated on the basis of total pressure generated by the heart and assuming a two-component model for heart muscle. In a recent, poignant critique of the measurement and interpretation of Vmax, Pollack has emphasized the importance of parallel elasticity in calculating Vce in cardiac muscle (17). Furthermore, he has shown that calculation of Vce using three com- ponent models provide an extrapolated Vmax which is both length dependent and influenced by the transient nature of the active state. Pollack suggests that the reported length independence of Vmax derived from afterloaded isotonic contractions is the result of an "unusually fortunate pattern of contribution of the series and parallel elastic components to the muscle force-velocity curve." It is entirely possible, therefore, that the Vmax values reported in the present study are also influenced by "other" factors in such a way as to fortuitously provide an index which is useful in estimating contractile state. There are, perhaps, several reasons why this may have occurred in the present study. First, left ventricular enddiastolic pressures were generally between 1 and $4 \mathrm{~mm}$ $\mathrm{Hg}$ and never exceeded $6 \mathrm{~mm} \mathrm{Hg}$. Thus, the vagaries of assuming a two component model are minimized, since the contribution of the parallel elastic component in a three component model would be small at these light preloads. Second, the experiments analyzed by Pollack were carried out in isolated muscle at $23^{\circ} \mathrm{C}$, where the maximum intensity of the active state is not achieved until $200 \mathrm{msec}$ after the onset of contraction (18-19). The 
present studies were done at body temperature (37$38^{\circ} \mathrm{C}$ ), where the onset of maximum active state is shortened to $40 \mathrm{msec}$ after the onset of pressure rise (20). Since the segment of the inverse curve used to extrapolate Vmax averaged only $27 \mathrm{msec}$ in control states and began at the time maximum active state was achieved, the influence of a transient active state upon these measurements of Vce should be substantially less in the intact dog than in isolated muscle experiments, particularly if one assumes relatively little change in intensity of the active state during the last $20-30 \mathrm{msec}$ of isovolumic systole (20).

The warnings made by Pollack, however, assume even greater proportions when these technics are extended to human studies. Obviously, the role of the parallel elastic component in influencing Vce will be substantially greater at high end-diastolic pressures, whether associated with less compliant, hypertrophied ventricles or longer sarcomere lengths. This issue is not yet settled, and it is noteworthy that Peirce, Kent, Patterson, and Temple have shown that $V \max$ derived from measurements of isovolumic Vce was independent of fiber length when calculated on the basis of total pressure. If, however, developed pressure was used to derive Vce, large variations in $V \max$ were observed with changes in diastolic fiber length (21).

Despite these considerations, in a study of forcevelocity relations throughout the isovolumic and ejection periods of subjects with aortic stenosis, Vmax was obtained by extrapolation of the inverse curves and found to correlate with other indices of left ventricular failure (22). More recently, Mason (10) has reported that Vmax may be extrapolated from measurements of Vce and pressure obtained during the isovolumic period only. While the potential advantages of this approach are obvious, there are a number of important limitations which should be stressed. Firstly, since this analysis depends upon a truly isovolumic period, it is not applicable in the presence of mitral regurgitation, ventricular septal defect, or ventricular aneurysm. Secondly, the segment of the inverse curve used to extrapolate $V \max$ is brief, averaging $27 \mathrm{msec}$ in control states and only $11 \mathrm{msec}$ during norepinephrine administration. Using conventional recording technics, accurate measurements of instantaneous $\mathrm{dp} / \mathrm{dt}$ and $\mathrm{P}$ are extremely difficult during this phase of systole, and measurements made at $5 \mathrm{msec}$ intervals may provide no more than two to three points from which to extrapolate Vmax. The high speed recordings employed in the present study resolve some of these difficulties, and the values of $V \max$ obtained by this method correlated well over a wide range with those derived from analyses of isovolumic contractions of the left ventricle (Fig. 3 ).
The values for $V \max$ found in this study are three times higher than those reported in humans by Mason (10). While the faster heart rates in our canine studies may be responsible for higher values of $V \max$, a more important factor is the constants used to express the series elasticity of heart muscle. In Mason's study, Vce was derived as $(\mathrm{dP} / \mathrm{dt}) / \mathrm{kP}+\mathrm{C}$, where $\mathrm{k}=40 \mathrm{~cm}^{-1} / \mathrm{cm}$ muscle length and $\mathrm{C}=80 \mathrm{~g} / \mathrm{cm}^{2}$. These figures represent the values found by Parmley and Sonnenblick in the isolated cat papillary muscle at $30^{\circ} \mathrm{C}(23)$. It has been shown subsequently that series elasticity is a function of temperature and that the modulus $\mathrm{k}$ falls from 40 to 32 $\mathrm{cm}^{-1}$ as the temperature is increased to $37^{\circ} \mathrm{C}$ (24). In addition, there is reason to believe that the series elasticity measured in the intact ventricle is less than that of isolated heart muscle. Forwand, McIntyre, Lipana, and Levine (12) reported that average modulus of series elasticity of the intact dog left ventricle was only 24 $\mathrm{cm}^{-1} / \mathrm{cm}$ of muscle length, and this value was used to calculate Vce in the present study. Parmley and Sonnenblick (23) have also shown that series elasticity is a function of preload and that increasing sarcomere lengths increases the value of the $\mathrm{dF} / \mathrm{dl}$ intercept of the linear plot of $\mathrm{dF} / \mathrm{dl}$ and $\mathrm{F}$, when $\mathrm{F}$ was calculated as developed tension. When total tension is calculated, however, it can be seen that series elasticity is not influenced by changes in preload (25). Thus, in calculations of Vce during the isovolumic contraction period, it is expected that series elasticity will not be influenced by changes in preload as long as force or pressure is measured from a true zero reference. While the manner with which the load is transferred from the parallel to the series elastic component is not fully understood, it is likely that the influence of the $\mathrm{dF} / \mathrm{dl}$ intercept upon the series elasticity during the second half of the isovolumic period is quite small. This constant also is diminished by increasing temperature and at $37^{\circ} \mathrm{C}$ has been found to be only 20 $\mathrm{g} / \mathrm{cm}^{2}$ (24). Although this constant has been assumed to be zero in the present calculations of Vce, its contribution to series elasticity will be progressively greater at lower values of isovolumic pressure.

A more important problem in the measurement of $V \max$ by this method concerns potential variations in the functional series elasticity of the diseased heart during the isovolumic contraction period. Although it has been shown that inotropic interventions do not affect series elasticity (8) and that both hypertrophy and myocardial failure do not influence the modulus of series elasticity (25), the extent to which mechanical asynergy may produce changes in active stiffness of the ventricle is not known. This consideration assumes importance, particularly in studies of the diseased human heart, since it has been shown that the functional series elasticity of the ventricle is decreased by experimental left ventricu- 
lar aneurysm (12). Since there is at present no way to measure series elasticity of the intact human heart, changes in Vmax detected by the method presented here may be due to changes in contractile state or to changes in active stiffness of the ventricle. For these reasons, measurement of isovolumic contractile element velocities should always be coupled with ventriculography in an effort to assess the contractile state of the intact venticle.

Preejection time intervals. In the present study max $\mathrm{dP} / \mathrm{dt}$ was always observed to occur before aortic valve opening, even during hypotensive states when the myocardium was depressed by large doses of barbiturates. While most workers concur with this observation (2629), Mason and his associates maintain that max $\mathrm{dP} / \mathrm{dt}$ "generally occurs at the maximum isovolumic pressure of ejecting beats" (30), and Wildenthal, Mierzwiak, and Mitchell (31) found that $\max \mathrm{dP} / \mathrm{dt}$ occurred at or within $5 \mathrm{msec}$ before aortic end-diastolic pressure. The latter workers reported that abrupt elevations of aortic pressure between two ventricular beats generally increased $\max \mathrm{dP} / \mathrm{dt}$ and delayed the time at which $\max \mathrm{dP} / \mathrm{dt}$ was achieved in the afterloaded beat. They concluded that aortic valve opening tends to limit $\max \mathrm{dP} / \mathrm{dt}$. In the present study, $\max \mathrm{dP} / \mathrm{dt}$ of single isovolumic beats was generally identical with that of the preceding auxotonic beat and a similar experience has been reported by others $(6,32)$. It should be noted that in the studies of Wildenthal et al., an air pump was used to elevate aortic pressures and central pulse pressures were unusually wide at the heart rates studied. Although aortic valve opening was not found to limit $\max \mathrm{dP} / \mathrm{dt}$ in the present study, the observations of Wildenthal and his associates may be applicable to certain abnormal hemodynamic states (ie. aortic insufficiency) and should be kept in mind in clinical studies of this type.

Indices of contractility. Variations in wall stress notwithstanding, single values of Vce might be expected to provide an estimate of the contractile state of the heart. Considering the shape of the classic force-velocity curve, one would predict that the highest single value of Vce during systole would provide a better approximation of V max and would be less influenced by loading conditions than subsequent lower values of Vce. If this is so, peak Vce should correlate better with Vmax than $\mathrm{V}$ ce at max $\mathrm{dP} / \mathrm{dt}$, which in turn should be better than a single value of Vce measured during the ejection period. While in the present study peak Vce appeared to be slightly better than Vce measured at $\max \mathrm{dP} / \mathrm{dt}$, measurements of the former were sometimes difficult to determine despite careful analysis of high speed recordings. Since peak Vce generally occurs at low ventricular pressures (average $32 \mathrm{~mm} \mathrm{Hg}$ in controls) and the validity of the expression $(\mathrm{dp} / \mathrm{dt}) \mathrm{kP}$ at low pressures depends upon accurate determination of reference zero, measure- ment errors of peak Vce may be considerable. Another explanation is that the atrial contribution of left ventricular isovolumic pressure rise may interfere with early determinations of Vce. For this reason it may be expected that even greater difficulties in measuring peak Vce will be encountered in clinical situations where left ventricular end-diastolic pressure is elevated. Because of its timing, the same considerations would apply to $\max \mathrm{d}^{2} \mathrm{P} / \mathrm{dt}^{2}$.

On the other hand, all values of $\mathrm{Vce}$ at $\max \mathrm{dP} / \mathrm{dt}$ fell on the inverse Vce-pressure curve, indicating that this single determination is a reliable and reproducible measurement of instantaneous Vce. In distinguishing between changes in preload and contractile state, Vce measured at max $\mathrm{dP} / \mathrm{dt}$ more closely paralleled Vmax than any of the other indices examined (Fig. 5). While $\max \mathrm{dP} / \mathrm{dt}$ itself is extremely sensitive to alterations in contractile state, it is influenced considerably by changes in fiber length. As these animals had intact baroreceptors, it is possible that volume loading did produce some alteration in contractile state despite a controlled heart rate. If such were the case, however, the effect was too subtle to be measured in these experiments.

The use of $(\max \mathrm{dP} / \mathrm{dt}) \mathrm{kP}$ as an index of contractility warrants several considerations. Firstly, identification of the exact pressure which exists at $\max \mathrm{dP} / \mathrm{dt}$ is extremely difficult with conventional pressure recordings. Furthermore, in the present study, all animals had normal left ventricles and, therefore, the good correlation between $\mathrm{Vmax}$ and $(\max \mathrm{dP} / \mathrm{dt}) \mathrm{kP}$ may have been due to the fact that significant variations in wall stress at a given Vce were not encountered in each experimental state.

The expression $(\max \mathrm{dP} / \mathrm{dt}) / \mathrm{PIP}$ has the advantage that it may be measured with considerable accuracy from conventional pressure recordings. In a study of subjects with normal and abnormal left ventricles, Frank and Levinson (33) measured $\max \mathrm{dP} / \mathrm{dt}$ and PIP both at rest and during exercise. Calculated from their data, (maximum $\mathrm{dP} / \mathrm{dt}$ )/PIP identified quite well those patients with myocardial failure. They suggested, however, that this expression be further divided by left ventricular end-diastolic circumference and by doing so achieved a clearer separation of the failing and non-failing heart. Since the failing heart generally has a larger end-diastolic circumference, this finding is predictable. However, the index proposed by Frank and Levinson does not have units of normalized velocity, since $(\max \mathrm{dP} / \mathrm{dt}) / \mathrm{PIP}$ is already normalized for fiber length (vide supra). Nonetheless, while their index does require measurement of ventricular volume, it appears to be useful in identifying myocardial failure in the human heart.

In addition to the limitations mentioned above, a further problem is encountered by substituting peak iso- 
volumic pressure for the instantaneous pressure which exists at $\max \mathrm{dP} / \mathrm{dt}$. In the present study $(\max \mathrm{dP} / \mathrm{dt}) /$ PIP provided a fair indication of changes in $V \max$ although less favorable than that found with ( $\max$ $\mathrm{dP} / \mathrm{dt}) / \mathrm{kP}$. This suggests that the ratio of $\mathrm{P}$ at $\max$ $\mathrm{dP} / \mathrm{dt}$ to PIP was reasonably constant in these experiments. Nonetheless, it may be expected that in patients with aortic valvular disease and low peak isovolumic pressures, this ratio may be quite abnormal. The supernormal values for $(\max \mathrm{dP} / \mathrm{dt}) / \mathrm{PIP}$ reported in patients with aortic stenosis (33) are high in part by virtue of a low PIP. In addition, a higher velocity measurement is to be expected at a given pressure in the hypertrophied ventricle, where a given value of pressure is shared by a greater number of sarcomeres in parallel and thus wall stress is reduced. Without invoking a change in the contractile state, the velocity measured at this pressure will be higher since each sarcomere is relatively less loaded.

In summary, using high speed recordings of isovolumic pressure and its first derivative, Vmax may be determined in auxotonic beats by extrapolation of a plot of Vce and pressure. While single measurements of isovolumic Vce are of some use in characterizing the contractile state of the normal ventricle, estimation of Vmax eliminates the problem of variations in wall stress and provides an absolute reference scale for assessing the the contractile state of the heart assuming that series elasticity is constant. When practical methods for measuring the series elasticity of the diseased heart becomes available, the extent to which passive elements within the ventricle influence the contractile process can be examined more thoroughly.

\section{ACKNOWLEDGMENTS}

The technical assistance of Mrs. Gainor Urian and Mrs. Theresa Boles, and the secretarial aid of Miss Sandra Bryan is gratefully acknowledged.

This work was supported by U. S. Public Health Research Grant HE 7139.

\section{REFERENCES}

1. Hill, A. V. 1938. Heat of shortening and the dynamic constants of muscle. Proc. Roy. Soc. Ser. B. Biol. Sci. 126: 136 .

2. Abbott, B. C., and W. F. H. M. Mommaerts. 1959. A study of inotropic mechanisms in the papillary muscle preparation. J. Gen. Physiol. 42: 533.

3. Sonnenblick, E. H. 1962. Force-velocity relations in mammalian heart muscle. Am. J. Physiol. 202: 931.

4. Fry, D. L., D. M. Griggs, Jr., and J. C. Greenfield, Jr. 1964. Myocardial mechanics: Tension-velocity-length relationships of heart muscle. Circ. Res. 14: 73.

5. Levine, H. J., and N. A. Britman. 1964. Force-velocity relations in the intact dog heart. J. Clin. Invest. 43: 1383.

6. Ross, J., Jr., J. W. Covell, E. H. Sonnenblick, and E. Braunwald. 1966. Contractile state of the heart charac- terized by force-velocity relations in variably afterloaded and isovolumic beats. Circ. Res. 18: 149.

7. Podolsky, R. J. 1962. Mechanochemical basis of muscular contraction. Federation Proc. (Washington). 21: 964.

8. Sonnenblick, E. H. 1962. Implications of muscle mechanics in the heart. Federation Proc. (Washington). 21: 975 .

9. Covell, J. W., J. Ross, Jr., E. H. Sonnenblick, and E. Braunwald. 1966. Comparison of the force velocity relation and the ventricular function curve as measures of the contractile state of the intact heart. Circ. Res. 19: 364.

10. Mason, D. T. 1969. Usefulness and limitations of the rate of rise of intraventricular pressure $(\mathrm{dp} / \mathrm{dt})$ in the evaluation of myocardial contractility in man. Amer. J. Cardiol. 23: 516 .

11. Levine, H. J., S. A. Forwand, K. M. McIntyre, and E. Schechter. 1966. Effect of afterload on force-velocity relations and contractile element work in the intact dog heart. Circ. Res. 18: 729.

12. Forwand, S. A., K. M. McIntyre, J. G. Lipana, and H. J. Levine. 1966. Active stiffness of the intact canine left ventricle with observations on the effect of acute and chronic myocardial infarction. Circ. Res. 19: 970.

13. Glick, G., E. H. Sonnenblick, and E. Braunwald. 1965. Myocardial force-velocity relations studied in intact unanesthetized man. J. Clin. Invest. 44: 978.

14. Sonnenblick, E. H., J. F. Williams, Jr., G. Glick, D. T. Mason, and E. Braunwald. 1966. Studies on digitalis XV. Effects of cardiac glycosides on myocardial force-velocity relations in the non-failing human heart. Circulation. 34: 532.

15. Gault, J. H., J. Ross, Jr., and E. Braunwald. 1968. Contractile state of the left ventricle in man. Instantaneous tension-velocity-length relations in patients with and without disease of the left ventricular myocardium. Circ. Res. 22: 451.

16. Noble, M. I. M., T. E. Bowen, and L. L. Hefner. 1969. Force-velocity relationship of cat cardiac muscle, studied by isotonic and quick-release techniques. Circ. Res. 24: 821.

17. Pollack, G. H. 1970. Maximum velocity as an index of contractility in cardiac muscle: A critical evaluation. Circ. Res. 26: 111.

18. Sonnenblick, E. H. 1965. Determinants of active state in heart muscle: force, velocity, instantaneous muscle length, time. Fed. Proc. (Washington). 24: 1396.

19. Brady, A. J. 1965. Time and displacement dependence of cardiac contractility: problems in defining the active state and force-velocity relations. Fed. Proc. (Washington). 24: 1410 .

20. Levine, H. J. 1967. Muscle mechanics in the in situ heart. In Factors Influencing Myocardial Contractility. R. D. Tanz, F. Kavaler, and J. Roberts, editors. Academic Press, New York. 93.

21. Peirce, E. C., II, B. B. Kent, R. E. Patterson, and J. Temples. 1970. A curious approximate construction for Vce max. J. Appl. Physiol. 28: 507.

22. Levine, H. J., K. M. McIntyle, J. G. Lipana, and O. H. L. Bing. 1970. Force-velocity relations in failing and nonfailing hearts of subjects with aortic stenosis. Amer. J. Med. Sci. 259: 79.

23. Parmley, W. W., and E. H. Sonnenblick. 1967. Series elasticity in heart muscle: Its relation to contractile element velocity and proposed muscle models. Circ. Res. 20: 112 . 
24. Yeatman, L. A., Jr., W. W. Parmley, and E. H. Sonnenblick. 1969. Effects of temperature on series elasticity and contractile element motion in heart muscle. Amer. J. of Physiol. 217: 1030.

25. Parmley, William W., James F. Spann, Jr., Roger R. Taylor, and Edmund H. Sonnenblick. 1968. The series elasticity of cardiac muscle in hyperthyroidism, ventricular hypertrophy and heart failure. Proc. Soc. Exp. Biol. Med. 127: 606 .

26. Gleason, W. L., and E. Braunwald. 1962. Studies on the first derivative of the ventricular pressure pulse in man. J. Clin. Invest. 41: 80 .

27. Reeves, T. J., L. L. Hefner, W. B. Jones, C. Coghlan, G. Prieto, and J. Caroll. 1960. The hemodynamic determinants of the rate of change in pressure in the left ventricle during isometric contraction. Amer. Heart $J$. $60: 745$.

28. Schaper, W. K. A., P. Lewi, and A. H. M. Jageneau. 1965. The determinants of the rate of change of the left ventricular pressure $(\mathrm{dp} / \mathrm{dt})$. Arch. Kreislaufforsch. 46: 27.

29. Siegel, J. H., E. H. Sonnenblick, R. D. Judge, and W. S. Wilson. 1964. The quantification of myocardial contractility in dog and man. Cardiologia (Basel). 45: 189.

30. Braunwald, E., J. Ross, Jr., J. H. Gault, D. T. Mason, C. Mills, I. T. Gabe, and S. E. Epstein: NIH clinical staff conference. 1969. Assessment of cardiac function. Ann. Intern. Med. 70: 369.

31. Wildenthal, K., D. S. Mierzwiak, and J. H. Mitchell. 1969. Effect of sudden changes in aortic pressure on left ventricular dp/dt. Amer. J. Physiol. 216: 185.

32. Taylor, R. R., J. Ross, Jr., J. W. Covell, and E. H. Sonnenblick. 1967. A quantitative analysis of left ventricular myocardial function in the intact, sedated dog. Circ. Res. 21: 99.

33. Frank, M. J., and G. E. Levinson. 1968. An index of the contractile state of the myocardium in man. J. Clin. Invest. 47 : 1615. 